\title{
Los significados de lo demoníaco: abstracciones del mal en la narrativa de Roberto el Diablo
}

\section{Meanings of the demonic: evil's abstractions in Roberto el Diablo's narrative}

\author{
Ricardo J. CASTRo García \\ El Colegio de México
}

\begin{abstract}
En este artículo el autor identifica conceptos abstractos implícitos en las características concretas que configuran al protagonista de Roberto el Diablo. Estas nociones pueden ser la subversión, la disformidad, la desproporción o la pluralidad. Una vez analizadas, se reconocen en la caracterización del protagonista de la novela. De esta manera, se registran y desconfiguran representaciones del mal en la cultura occidental por medio de un popular y tradicional personaje del folclor europeo. Se trata, por tanto, de un estudio sobre las figuraciones de lo diabólico, y de su puesta en práctica en una obra española del siglo xvi.
\end{abstract}

Palabras Clave: Roberto el Diablo, demonio, diablo, filosofía, mal, literatura de cordel

In the paper "Los significados de lo demoníaco: abstracciones del mal en la narrativa de Roberto el Diablo" "The Meanings of the Demoniac: Abstractions of Evil in the Narrative of Roberto el Diablo"), the author identifies abstract concepts that are implicit in the concrete features that define the main character of Robert le Diable. These notions may be: subversion, deformity, disproportion or plurality. In this way, representations of evil in Western culture are registered and deconfigured thorough a popular and traditional character of European culture. Thus, it is a study of the forms and conceptualizations of the diabolical, and its application in a $16^{\text {th }}$ century Spanish play.

KEYwORDS: Roberto el Diablo, demon, devil, philosophy, evil, cordel literature

$\mathrm{E}$

n 1973, buena parte de la humanidad tuvo la misma pesadilla. Regan, la protagonista de El exorcista, bajaba las escaleras de espaldas arqueando al límite su infantil columna. Unos años después, Kubrick, en El resplandor, filma una de las escenas más inquietantes del cine: las hojas de una gruesa novela son descubiertas por la esposa del escritor. En ella sólo está mecanografiada una y otra vez la misma frase ad nauseam.

En estas escenas hay algo que rebasa la salud ortopédica de una niña o el minimalismo radical de un escritor. Son expresiones mediatas de lo que significa 
el mal. En un caso se manifiesta la inversión de la realidad como se supondría que debería ser (bajar las escaleras de pie y de frente); y en otro, la locura y el vacío de sentido (expresado en una posible trama). Se tratan de figuraciones de lo demoníaco. Es decir, hay una representación plástica o narrativa que expresa un concepto relacionado directamente con el mal, ya sea como trasgresión, inversión, sinsentido, desviación. Por ejemplo, si el sujeto considerado maligno resulta ser zurdo, no es porque la mano izquierda haga cosas negativas por definición, sino que se establece un indicio que se relaciona con lo invertido.

Así, muchos de los elementos que caracterizan a un personaje demoníaco — más allá de lo grotesco, desagradable o inmoral— implican ideas tales como la desproporción, la insensatez o el absurdo. No es lo mismo decir que un perro atacó a un niño, que identificar al animal como una criatura negra, con ojos rojos y un lunar con forma de $S$ en la frente. En el primer caso hablaríamos de un hecho lamentable con muchas explicaciones posibles. En el segundo operan significaciones culturales inscritas en la intimidad de la moral y la teología europeas. Ese perro deja de ser un animal y se convierte en una representación gracias a sus insignias reconocibles para el horizonte cultural judeo-cristiano.

El propósito del presente trabajo es la identificación de conceptos abstractos implícitos en las características concretas que configuran al protagonista de Roberto el Diablo. Me explico: sabemos de la maldad del personaje desde el título del relato y por las conductas que desarrolla a lo largo de la obra. No obstante, al margen de los juicios del narrador y del texto mismo, lo demoníaco forma parte de la caracterización del personaje mediante elementos que aluden a una idea del mal inscrita en el horizonte cultural. Por ejemplo, Roberto, desde bebé, tiene dientes con los que arranca los pezones de las mujeres que intentan darle de comer; o bien, desde niño cuenta con una fuerza desmedida. Además de la violencia que esto implica, en el primer caso hay una profanación de la figura materna, tan importante para el catolicismo; así como una proclividad por el uso de la fuerza física en detrimento del entendimiento, una de las tres potencias del alma que nos separan de lo animal y lo irracional. En ambos ejemplos no sólo se representa la maldad de manera directa, como violentación e indecorosidad. Sobre todo, actúan narrativamente conceptos que involucran la trasgresión o la inversión de un orden y de un sistema de creencias. Los dientes y la fuerza del niño son, respectivamente, expresión y profanación de la amorosa protección materna y de lo razonable. 


\section{DEL MAL ABSTRACTO AL MAL CONCRETO Y NARRATIVO}

Lo diabólico ha sido pensado durante milenios y entendido de manera teórica como la ausencia de gracia divina o como la perversión cósmica de un orden. Sin embargo, dicho de modo tan abstracto, apenas indigna. De tal manera, es necesaria la representación concreta de dichas nociones para dar cuenta de su significación.

Por ejemplo, es tradicional la capacidad del diablo de tomar cualquier forma; cuenta, pues, con una asombrosa versatilidad plástica. A veces puede ser una mujer, un perro o un chivo. Cada una de estas figuras por sí solas no representan necesariamente al diablo, sí su facultad de ser todas. $\mathrm{Al}$ respecto, en los Evangelios, Jesucristo señala que él es "el camino y la verdad" mientras que su antagonista expresa: "Mi nombre es legión", es decir, muchos. Se oponen dos nociones: la de la unidad y la de lo múltiple. Lo bueno se corresponde con lo estable y lo uniforme; lo demoníaco, con lo vacilante e incluyente. El diablo, entonces, aparecerá inconsistentemente como animal o niebla, denotando su naturaleza ambigua. Volviendo a los primeros ejemplos, cuando Regan baja las escaleras de espaldas (la subversión) o un escritor redacta la misma frase una y otra vez (el frenesí y el absurdo) hay nociones de lo demoníaco entrando en juego, y que el receptor reconoce como amenazantes e inquietantes, la mayoría de las veces, de forma inconsciente.

De tal manera, en el arte, la identificación de las características de lo demoníaco y la reflexión sobre su significado pueden dar luz sobre la configuración de elementos reconocidos como perversos. Tal es el caso del protagonista de Roberto el Diablo. A lo largo del presente trabajo iré revisando algunas de las características que definen a este personaje como un ser diabólico, y sus implicaciones.

\section{Roberto: ¿Diablo Popular o CUlto?}

Esta novela contiene elementos tradicionales. Aparece por primera vez en Francia en el siglo xiII bajo la forma de un exemplum para después pasar al miracle. A finales del siglo $\mathrm{xV}$, se publica el roman lionés La vie du terrible Robert le Diable, que se traduce al español. La historia de esta tradición ${ }^{1}$ nos interesa dado que para penetrar en el análisis de la configuración diabólica del

1 Para una mayor profundidad del tema de la tradicionalidad de la obra véase Cacho Blecua, "Estructura y difusión”, y Gaucher, "Robert le diable”. 
personaje es necesario identificar desde qué horizonte cultural se produce, si desde el popular o el letrado.

El demonio tiene dos versiones de sí mismo. Desde un horizonte letrado, se construye sobre la idea de ser la quinta esencia de la corrupción, el vacío y el mal. Dicha construcción se elabora desde la teología, la elite y los discursos oficiales y moralizantes. Por su parte, la cultura popular crea un diablo más cercano y concreto, tendiente a lo cómico y a lo grotesco, vulnerable a veces, casi humano.

Como casi todo lo real, las distinciones teóricas son funcionales sólo como punto de partida conceptual y para situaciones paradigmáticas. En el caso de Roberto el Diablo ambos afluentes culturales confluyen. Al respecto, Elizabeth Gaucher explica que las versiones francesas anteriores al siglo XV estaban pensadas para un público culto y que, con la imprenta, Robert le Diable se vulgariza hasta llegar a la literatura de cordel del XIX. ${ }^{2}$

Vayamos a la versión española. Nieves Baranda señala que la primera parte de la obra "tiene elementos de sermón, comenzando por el exordio [...]. La historia que sigue es, pues, un ejemplo del que debe aprender el lector para llegar a la salvación [... ]" (Baranda, Historias caballerescas del siglo XVI, L). Lo que me importa destacar al respecto son dos cosas, el carácter moralizante y la voz erudita del narrador. Éste señala lo siguiente en las primeras líneas de la obra: "[...] así como nos muestra Boecio, De consolación, sin la cual ninguna cosa puede tener buen comienço [... sin que la gloriosa Madre sea nuestra medianera, como Sant Agustín escribe [...]”. A partir de estos referentes, se deduce el tipo de horizonte cultural desde donde se enuncia la obra. Podríamos considerar que se trata de un ejemplo de literatura construida a partir de nociones teológicas, lo que nos haría pensar en un relato escrito desde y para la alta cultura. Sin embargo, esto va a ser problemático si tomamos en cuenta el carácter tradicional del relato, su difusión, popularidad y vigencia hasta el

2 Al respecto: "La naissance de l'imprimerie, puis l'apparition d'éditions à bon marché, qui ont permis une diffusion massive des romans de chevalerie, coïncident avec l'abandon, dans les milieux lettrés, de ce type de récit au profit des ouvrages humanistes. Se constitue alors un clivage entre une culture d'élite, nourrie d'Antiquité gréco-latine, et une culture populaire, encore attachée à la littérature chevaleresque. Ainsi s'explique la dérive sociale de Robert le diable au fil de ses éditions successives. Ecrit au XIIIe siècle, le roman s'adresse d'abord à l'aristocratie aisée, comme en témoigne le soin apporté à la confection des manuscrits et des premiers incunables. Mais au début du Xvire siècle, il quitte la haute sphère des imprimeurs à privilège et ses libraires, pour entrer dans la Bibliothèque bleue et pénétrer dans les milieux populaires sous la forme de courts livrets grossièrement façonnés." ("Robert le diable”). 
cine del siglo xx y el cómic contemporáneo. ${ }^{3}$ Se trata, entonces, de un relato enunciado desde una cultura letrada cuyo público puede o no ser culto. Esta situación es muy ilustrativa para el tema de la distinción entre el diablo culto y el popular, ${ }^{4}$ dado que a veces se establece como modelo teórico uno u otro cuando en la práctica hay una invasión mutua.

En la versión española de Roberto el Diablo del siglo XVI, las nociones profundas de lo demoníaco operan bajo la forma de un relato con marcas populares y tradicionales, lo que llevaría a pensar que las nociones teológicas de lo diabólico no son exclusivas de la alta cultura o que se enuncian desde un interés religioso de elite, como lo manifiesta en general Robert Muchambled; sino que esas abstracciones del mal fueron asimiladas por la cultura popular $\mathrm{y}$ tradicional.

\section{LA INSATISFACCIÓN}

El padre de Roberto, Aubert, es un duque "noble, discreto, esforçado, benigno y muy humano", además de "muy querido de sus vasallos" (548). Su matrimonio es también fruto de una calculada decisión. Hay, pues, un origen ilustre y un escenario favorable y justo. Sin embargo, una condición no satisface al duque en medio de la bienaventuranza: la esterilidad. El narrador, que habla desde una moral religiosa que exalta la resignación y la humildad, parece no darle mucha importancia en un primer momento a esta anomalía:

Porque muchas vezes es mejor carescer de hijos que tenerlos, y más a salvación de las ánimas al padre y a la madre nunca aver engendrado ni concebido que tener hijos, si por falta de doctrina son condenados. Por ende digo avemos de pedir a Dios salvo que a nuestra salvación pertenesce y más a su servicio y voluntad fuere (548).

No obstante, hay que tomar en cuenta la importancia de la descendencia para el orden medieval. Dice el historiador George Duby acerca de

3 A este respecto, son muy puntuales los paralelismos que encuentra Santiago Cortés Hernández entre el cómic de Hellboy y la obra que aquí nos ocupa ("De Roberto el diablo a Hellboy").

4 Este tema lo trata de manera general Robert Muchambled en Historia del diablo. Siglos XII-XX, y en el ámbito hispánico José Manuel Pedrosa en "El diablo en la literatura de los Siglos de Oro".

Medievalia 48, 2016, pp. 157-169 
la unión matrimonial y, por ende, de la descendencia: "El matrimonio, en el seno del sistema de valores, se sitúa en la confluencia de lo material y lo espiritual. Por él se ve regularizada la transmisión de las riquezas de generación en generación; sostiene, por consiguiente, las 'infraestructuras' [...]” (El caballero, la mujer y el cura, 26). Si tomamos en cuenta que en el feudalismo las infraestructuras no eran precisamente sólidas, tenemos que la familia y la descendencia son de los pocos medios por los cuales el tan vulnerable orden social, económico o político podía sostenerse, o, por lo menos, reforzarse. El recelo por la esterilidad no podía ser cosa baladí para Aubert. De aquí que esté justificada la insatisfacción y el deseo de una realidad distinta. Tenemos, en este momento del relato, la decepción de lo que es y la idea, cada vez más urgente, de que todo podría ser de otra manera.

Las representaciones narrativas de lo demoníaco tienen paralelismo con el relato de Luzbel, quien era bueno y bello, pero se rebela a partir del orgullo y de saberse extraordinario. De igual manera, en la inquietud del duque está ya el germen de la rebeldía y su consecuente carácter diabólico: el capricho disfrazado de una buena intención. Enrico Castelli, quien piensa lo demoníaco desde la filosofía, señala que:

[... un capricho no tiene continuación, es la expresión de una soledad y, al mismo tiempo de lo posible. Esto es lo monstruoso. Un capricho enternece cuando los caprichos que le siguen se presentan encaminados a un final feliz [... ] lo infernal de una vida es el sentimiento de lo posible no realizado. Cuando decimos: "Habría podido realizar aquella acción... Todo sería tan diferente..., creamos una situación dolorosa (deplorar algo) que se torna infernal (monstruosa) si la idea de lo diferente (de lo otro que no ha sido) es la única dominante (Lo demoníaco en el arte, 93).

Eso diferente será inscrito en la mente del duque, y el artífice no es otro que el diablo:

Y como el enemigo de la humana generación siempre trabaja por privarnos de la gloria celestial, ármanos lazos porque cayamos en pecado mortal, y dexando el duque en el mal propósito y voluntad que oyestes fue a la duquesa y turbóla assimesmo en tanto grado que no sabía si estava en el mundo o fuera dél [ ... (551).

El duque se introduce en un proceso de obsesión por cambiar su situación y termina afectando su entorno. Se deja dominar por eso que Castelli 
llama "lo posible no realizado"; que en este caso encarna en el nacimiento de un heredero. El valor de la resignación desaparece paulatinamente y lo sustituye el capricho.

Hasta este momento, en el origen de los intereses del duque no hay perversidad, sólo una insatisfacción que crece como obsesión hasta resolverse en rebelión y convertirse finalmente en mal. Ahora, como señala Castelli, es importante destacar esa inadvertencia de lo demoníaco. La maldad de Roberto no se explica como corrupción pura. La fuente del mal no puede ser reconocida a primera vista. Debe emerger subrepticiamente sobre las buenas conciencias, sobre la voluntad de ser mejor, dado que la principal característica de lo diabólico es la inclinación hacia lo disforme, lo indefinido hasta llegar al absurdo, al sinsentido y, por último, a la nada que es la condición última de lo demoníaco.

\section{LA INDIVIDUALIDAD}

El duque va de caza y queda en soledad en medio del bosque. Ahí, su capricho y obsesión se reafirman. Maldice la hora en la que nació ya que se "quexaba del poder y de los hechos de Dios que tan desdichado le consentía ser y tan sin ventura que los inocentes vasallos por ello padeciessen" (550). Se convence de la legitimidad de su descontento. Hay una negación del orden tal cual es. Entonces, la autoridad, Dios, lo regular y el orden son valorados como injustos e innecesarios. La tentación está consumada.

En el momento de la concepción de Roberto dice la duquesa: "-Agora concibiesse yo y fuesse del diablo, pues que Dios no lo quiere, y assí gelo ofrezco y hago presente si concebir me haze $[. .]-$.$Y assí fue que por volun-$ tad de Dios concibió un hijo que fue muy perverso [...]” (551). Aquí está en funcionamiento el libre albedrío, concepto sustancial para la cristiandad. El tema es demasiado complejo para tratarlo aquí, pero hay que destacar que la libertad otorgada por Dios está siendo orientada hacia la contravención de un orden. Esto nos habla de una de las cualidades del diablo: la individualidad radical. Prudencio, el poeta cristiano de la Antigüedad tardía, dedica un pequeño poema al origen del mal, Hamartigenia. Giovanni Papini lo reseña en su ensayo El diablo y señala que éste "trató de hacer creer a los demás Ángeles que él era el autor y creador de sí mismo y que, por lo tanto, no debía a Dios su existencia” (El diablo, 27). Uno de los rasgos del demonio que seducen a los románticos es su titanismo. Cita el mismo autor italiano a Schiller: "El ser que se atrevió a desafiar al Omnipotente, ¿no era un genio extraordinario?” 
(Schiller, apud, Papini, 193). Ahora bien, la interpretación de Schiller es típica del Romanticismo, mismo que idealizó lo "otro", y las fuerzas oscuras de las conciencias. En la Edad Media, en cambio, ese individualismo no tenía ese halo heroico. Era una amenaza real e indeseable. Como ya señalé arriba, la sociedad encontraba en la familia y en lo comunitario el medio para sostener las instituciones que podían ofrecer algún tipo de seguridad. El individualismo resultaba entonces en un rasgo ciertamente amenazante para los intereses de los sujetos y de la sociedad. Este rasgo tendrá relación íntima con otro tal vez más significativo: el de la marginalidad, puesto que esa individualidad se resolverá en una separación, uno de los ejes del drama del diablo, tema que trataré más adelante.

\section{LA MONSTRUOSIDAD}

La monstruosidad de Roberto se augura desde el alumbramiento y sus primeros días de vida:

$[\ldots]$ y estuvo un mes de parto $[\ldots]$ de un día de nascido parescía de un año $[\ldots]$ mas dende a tres meses tuvo sus dientes y muelas, con los que les mordía las amas y les quitava los peçones de las tetas. [... ] Creció este niño mucho en poco tiempo, y si crescía en cuerpo, más crescía en maldades (552-553).

La desproporción y la deformidad son cualidades reconocibles del mal. No obstante, ¿qué condición proyectan? La respuesta merece una reflexión aparte. Podemos, mientras tanto, distinguir algunas nociones teóricas de la relación entre lo diabólico, la monstruosidad y la desproporción. La condición primaria de lo demoníaco es la ausencia de ser, mientras que la de Dios es la de lo absoluto e infinito. Sin embargo, estas condiciones, por su carácter definitivo y abstracto, son poco representables.

Pasemos ahora de lo abstracto a una imagen elemental. ¿Qué figura matemática se relaciona con lo divino? En el siglo XII aparece un enigmático texto con veinticuatro definiciones de Dios. Una de ellas indica que "Dios es una esfera infinita cuyo centro se halla en todas partes y su circunferencia en ninguna" (El libro de los veinticuatro filósofos, 47).

La circularidad - como expresión de equilibrio-y la presencia de un centro son la versión geométrica y primitivamente visual de la presencia de Dios. Por tanto, lo proporcionado será tradicionalmente bello. Si lo bello es la proporción (cuyo máximo exponente es el círculo), entonces, la disonancia, la desproporción, lo desmedido y la exuberancia serán manifestaciones del mal. 
$\mathrm{Al}$ respecto de la desproporción, Castelli dice "El pecado de lo sensible es el exceso. La voluptas es una ilícita extensión de los sentidos, un desequilibrio. Pecado de formación por súper-formación" (Lo demoníaco en el arte, 85). La desproporción y la monstruosidad nos hablan de una disgregación en la que el sentido (el camino y la verdad) se confunde; en segundo lugar, de la desviación y la separación. Al final de cuentas, esto fue lo que hizo el demonio con sus huestes: dividir.

Estas características se reconocen en la configuración física de Roberto, la cual, a su vez, representa su condición moral. La desproporción de su tamaño y su singularidad son predicciones plásticas del desorden que provocará en cada ámbito en el que se le admite. Por ejemplo, sus actos sanguinarios no son particularmente precisos, y se caracterizan por el desconcierto: "Y a otros desmembrava miembro a miembro y los derramaba por el monte. Y otros desmenudava en carnes y los colgaba por los pies de un árbol” (558). Tal irregularidad se presenta en cada aspecto y ante cualquier tipo de convención: “[... ] siguiendo todos los apetitos de la carne, y comía viernes y sábados carnes y en todas las vigilias, haziendo todos los días iguales” (559). Estos actos son la concreción narrativa de lo que expresa la desproporción física de Roberto, y ésta es, a su vez, la expresión del desorden que sobreviene en monstruosidad.

\section{LA MARGINALIDAD}

La exclusión de ese círculo divino deviene en marginalidad. Si hay desorden y desproporción no se puede participar de la institución, sea ésta la corte, la sociedad, el lenguaje o las reglas convenidas. Si el instrumento no sigue la partitura, el ejecutante insurrecto, además de llamar en ese momento la atención, será apartado de cualquier futuro programa. Esta condición es propia del diablo y de Roberto. A uno se le excluye de la gloria eterna y de la consideración del Todopoderoso, el otro es vilipendiado por sus congéneres y se aparta de la corte de su padre, de la ciudad y de la convivencia funcional y civilizada. La marginalidad de Roberto se expresa desde su infancia:

No los dexaban salir de casa con temor que con ellos topasse Roberto, y algunas vezes se juntavan muchos niños para pelear con él; mas ni porque fuessen muchos ni pocos no dexaba de los acometer, o con piedras o con palos, y algunas vezes lo descalabravan, mas siempre avía muchos dellos heridos y maltratados (553). 
La sociedad infantil lo identifica como anormal y desde su franqueza que no toma en cuenta jerarquías (Roberto será un monstruo, pero es hijo del duque) lo proscribe de su ámbito de juego y camaradería. Así es como esa desproporción hace que el protagonista sea rechazado.

El otro ámbito al que todavía pertenece es al de su familia y por tanto al de la nobleza. Esto es importante destacarlo. Roberto no es cualquier individuo, su ascendencia es ilustre y virtuosa, es decir, poderosa y buena. De nuevo, Roberto le hace justicia a su mote. Satán era el preferido de los cielos. Su belleza y dignidad procura un mayor dramatismo a su tragedia. La caída es ejemplar por su singularidad y por sus dimensiones. De tal manera, si Roberto fuera un villano más, su rebeldía tendría otros carices. $\mathrm{Al}$ ser un miembro de la nobleza y estar envuelto en un ámbito ejemplar, su marginalidad es más inquietante. Dicha condición se termina de establecer una vez que ha sido, calamitosamente, armado caballero, es decir, cuando el ritual de su madurez se ha estropeado por completo. Una vez que se ha convertido en un turbulento adulto: "allegó todos los que halló de su condición y salió de la ciudad con ellos, y quantos encontrava matava y rovaba [... ]” (556). Su condición marginal es definitiva.

\section{LA PLURALIDAD}

Uno de los momentos más elocuentes del diablo en los Evangelios es su lapidario legio mihi nomen est. Soy muchos, soy todos. En contraparte, Dios es el "ser" absoluto y no da lugar a ambigüedades. Al ser totalidad es unidad. Todo lo que tiene solidez huye de los márgenes y de los límites difusos. Una de las sentencias más celebradas de Cristo es la de declararse El camino y La verdad. La naturaleza del diablo, por el contrario, es la del "no ser”. Es legión, es posibilidad y potencialidad, es todos, pero nadie a la vez.

Cuando Roberto huye lleva consigo una suerte de corte de bandidos, conformada por los marginados, los relegados, los criminales: "y dende a pocos días supieron cómo estava con grande compañía de ladrones, robando y matando [... " (557). En su huida, las huestes se procuran una tosca sociedad: "Y en un lugar muy apartado ordenaron de hazer una casa donde se acojessen y defendiessen. Y hecha la casa, allegaron más gente y cogían ladrones, robadores, salteadores y matadores y todos los que de mal bivir y de seguir sus pisadas desseo tennían" (557-558).

La sociedad demoniaca está conformada por ángeles proscritos e individuos insumisos. Si a esta sociedad, la del diablo y la de Roberto, la traducimos 
a una unidad conceptual parecería que "el ser dinámico, tumultuoso, indefinido, proteico, psicológicamente agresivo, repugnante o seductor es una característica peculiar de lo demoníaco" (Castelli, Lo demoníaco en el arte, 18). Así, Roberto atrae hacia su figura todo lo que no atienda al orden institucional, todo aquello que no sea como se supone debe ser, y, a partir de ahí, funda una nueva comunidad.

\section{LA INVERSIÓN}

La inversión es una de las marcas de lo diabólico más importantes, dado que es el emblema de la subversión. De hecho, buena parte de lo que hemos mencionado deriva, en alguna medida, en ella. Por ejemplo, la sociedad criminal de Roberto reproduce una estructura social bajo criterios y normas subvertidas. Lo mismo podemos pensar del niño asesino o del rito de iniciación caballeresca que deriva justamente en la execración de la ceremonia: "La mesma noche veló Roberto el Diablo en la iglesia como es costumbre a los que han de seer armados cavalleros. Y en toda la noche no cessó de hazer mal a los que en la iglesía estavan" (555). Así, la forma más clara en la que se manifiesta la inversión es por medio de una suerte de parodia de lo sagrado, lo institucional o lo normativo; o bien, bajo la forma de la profanación.

En la novela encontramos una forma de inversión muy significativa que tiene que ver con la simbología numérica. A lo largo del relato resulta significativo el número siete. Dicho número tiene fuertes connotaciones religiosas folclóricas dado que "el pueblo hebreo sacralizó con tal número, uno de los más destacados en la aritmología bíblica, hechos, objetos e instituciones. A base de heptadas y en formulación catequética se narraba la actividad divina, y se regulaban los tiempos sagrados, el trabajo y el culto" (Tejero, "El siete, número cósmico", 223). Es decir, el siete define los ciclos de actividad divina y da cuenta de la completud de un desarrollo. En Roberto el Diablo el siete funciona bajo propósitos subvertidos, por tanto, da cuenta del proceso de degradación. Cada que el siete aparece, se cierra un ciclo progresivo de la maldad del protagonista. A los siete años Roberto comete su primer asesinato con su maestro de las siete artes liberales. Una vez que ya vive en el bosque, ejecuta a siete ermitaños alcanzando con ello el punto álgido de su perversión. Así, a la manera de la cruz invertida, de la misa oficiada por un burro o de las grabaciones de música reproducidas al revés, el descenso de Roberto hacia una moral cada vez más comprometida con su condición demoníaca se consolida con actos en los que se ve involucrado el número que se asocia "con 
la idea de periodo lleno o completo, y con el concepto de un todo acabado y perfecto" (Tejero, "El siete, número cósmico”, 223).

El ejemplo del uso dislocado del número siete es un ejemplo de las inversiones que implica todo contenido diabólico. La inversión, al final de cuentas, es uno de los rasgos más característicos de lo demoníaco y mucho de lo comentado sobre la marginalidad, la inconsistencia, el vacío de significación o lo proteico tiene su expresión más acabada en la subversión de un orden.

\section{CONCLUSIONES}

Roberto el Diablo es un excelente ejemplo de la manera en la que operan las nociones del mal en la cultura, pues en la novela cobran forma narrativa conceptos propios que le atañen, tales como la marginalidad, la monstruosidad o la trasgresión. Estas ideas calan en el imaginario por medio de representaciones literarias o plásticas que las ilustran y las ponen en funcionamiento. Tales nociones dibujan por medio del relato un rostro reconocible y definido, se vuelven personaje, acción y escenario. En otras palabras, en Roberto el Diablo entran en operación estos conceptos abstractos del mal de manera concreta y literaria. De tal manera, cuando el personaje es un ser que nace bajo la injuria divina, crece desproporcionadamente, arranca los pezones durante su lactancia, su entorno se desordena, o se margina acompañado de lo menos ilustre de su sociedad, entran en juego figuraciones que apelan a características reconocibles de lo demoníaco.

Roberto nace bajo el signo de la maldad: “ $\mathrm{O}$, misericordioso y eterno Dios! ¿Cómo permites que pague la inocencia del hijo la malicie de la madre? ¡O, pecador de mí!, quánto tiempo he servido al diablo sin tener conoscimiento de mi perdición!” (561). Dada la condición fatal de Roberto, éste reproduce a cabalidad los atributos diabólicos. Su perversión lo define y su relato es figuración de la del diablo, de aquí que sus características sean tan consistentes, funcionales y transparentes. Con la conversión, la naturaleza de Roberto cambia, como lo indica el cambio de nombre, Roberto Hombre de Dios.

\section{BIBLIOGRAFÍA}

Cacho Blecua, Juan Manuel, "Estructura y difusión de Roberto el Diablo", en Yves-Renè Fonquerne y Aurora Egido (eds.), Formas breves del relato, Zaragoza: Universidad de Zaragoza-Casa de Velázquez, 1986, 35-55. 
CAstelli, Enrico, Lo demoníaco en el arte. Su significado filosófico, Madrid: Siruela, 2007.

Cortés Hernández, Santiago, "De Roberto el diablo a Hellboy: dinámica de una narrativa de un héroe de la Edad Media al cómic”, Revista de Literaturas Populares, 8:2, 2008, 376-410.

Duby, GeORge, El caballero, la mujer y el cura. El matrimonio en la Francia feudal, trad. de Mauro Armiño, México: Taurus, 2013.

GAUChER, ÉLISABETH, "Robert le diable: une 'œuvre ouverte”, Cahiers de Recherches Médiévales, 2, 1996. En línea: http://crm.revues.org/2483

Lecentini, Paolo (ed.), El libro de los veinticuatro filósofos, Madrid: Siruela, 2002.

Muchambled, Robert, Historia del diablo. Siglo xiI-Xx, México: Fondo de Cultura Económica, 2006.

Papini, Giovanni, El diablo, Barcelona: Backlist, 2011.

Pedrosa, José Manuel, "El diablo en la literatura de los Siglos de Oro: de máscara terrorífica a caricatura cómica”, en María Tausiet y James S. Amelang (eds.), El Diablo en la Edad Moderna, Madrid: Marcial Pons Historia, 2004, 67-98.

Roberto el diablo, en Historias caballerescas del siglo XVI, ed. y prólogo de Nieves Baranda, Madrid: Turner, 1995, t. 1, 545-584.

Tejero Robledo, Eduardo, "El siete, número cósmico y sagrado. Su simbología en la cultura y rendimiento en el Romancero", Didáctica. Lengua y Cultura, 15, 2003, 221-253. 